\title{
Evaluation of selected methods of the heat transfer coefficient determination in fin-and-tube cross-flow heat exchangers
}

\author{
Tomasz Bury*, and Małgorzata Hanuszkiewicz Drapała \\ Institute of Thermal Technology, Silesian University of Technology, ul. Konarskiego 22, 44-100 Gliwice, Poland
}

\begin{abstract}
The work is a part of a thermodynamic analysis of a finned cross-flow heat exchanger of the liquid-gas type. The heat transfer coefficients on the liquid and the gas side and the area of the heat transfer are the main parameters describing such a device. The basic problem in computations of such heat exchangers is determination of the coefficient of the heat transfer from the finned surfaces to the gas. The differences in the heat transfer coefficient local values resulting from the non-uniform flow of mediums through the exchanger complicates the analysis additionally. Six Nusselt number relationships are selected as suitable for the considered heat exchanger, and they are used to calculate the heat transfer coefficient for the air temperature ranging from $10^{\circ} \mathrm{C}$ to $30^{\circ} \mathrm{C}$ and for the velocity values ranging from $2 \mathrm{~m} / \mathrm{s}$ to $20 \mathrm{~m} / \mathrm{s}$. In the next step, the gas-side heat transfer coefficient is determined by means of numerical simulations using a numerical model of a repetitive fragment of the heat exchanger under consideration. Finally, the Wilson plot method is also used. The work focuses on an analysis of the in-house HEWES code sensitivity to the method of the heat transfer coefficient determination. The authors believe that the analysis may also be useful for the evaluation of different methods of the heat transfer coefficient computation.
\end{abstract}

\section{NOMENCLATURE}

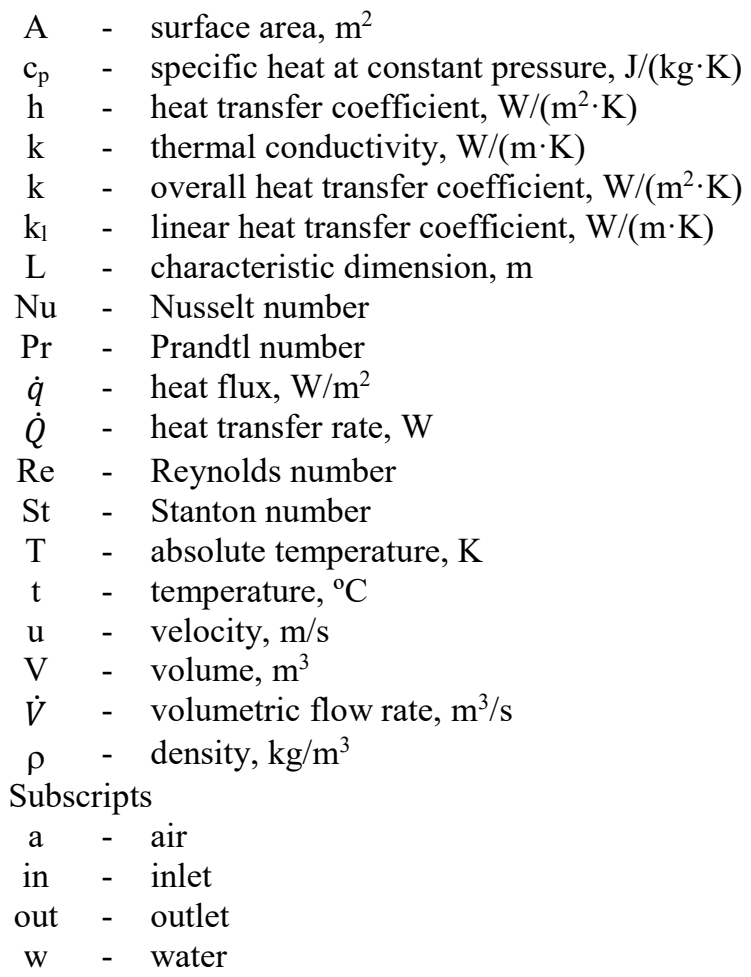

Note: Some specific symbols are explained in the text and in Fig. 4.

\section{Introduction}

\footnotetext{
*Corresponding author: tomasz.bury@polsl.pl
}

The paper presents a part of a thermodynamic analysis of a finned cross-flow heat exchanger of the liquid-gas type. The analysed device, presented in Fig. 1, is a typical car cooler characterized by a non-uniform inflow of air.

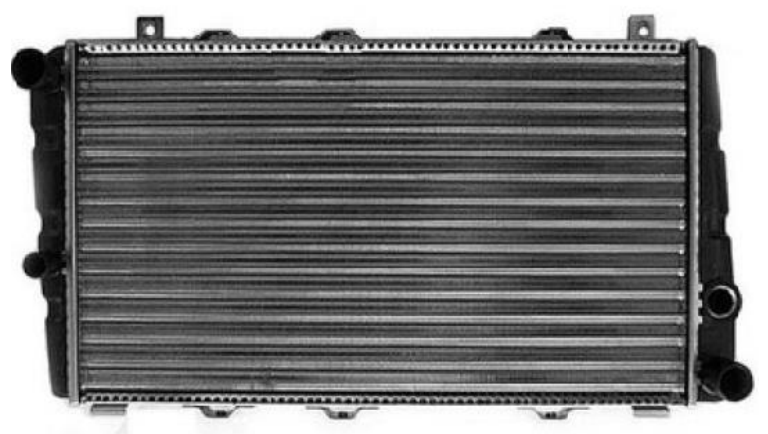

Fig. 1. View of the analysed heat exchanger

The measurements were performed on a test stand specially designed and made in the Institute of Thermal Technology of the Silesian University of Technology to enable testing of cross-flow heat exchangers to determine the form of the uneven air flow distribution at the inlet cross-section of the analysed heat exchanger. The test stand diagram is presented in Fig. 2. The stand main element is a thermoanemometric sensor. Figure 3 presents an example air velocity distribution at the analysed heat exchanger inlet. It should be noted that the air inflow has a non-uniform character. 


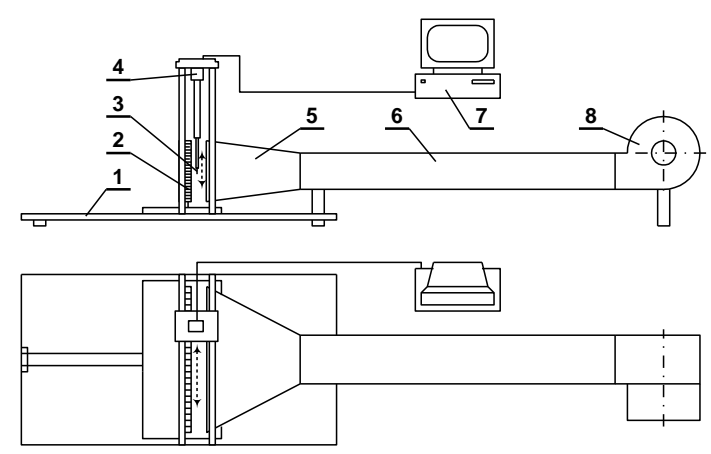

Fig. 2. Test stand - diagram of the air supply module 1 - support plate, 2 - heat exchanger, 3 - thermoanemometric sensor, 4 - measuring probe drive, 5 - diffuser, 6 - air channel, 7 - control computer, 8 - radial fan

The results of the measurements are used to develop a mathematical model of the heat exchanger under consideration. The model utilizes the finite difference method. The final effect of the analyses is a computer code, called HEWES, intended for thermal analyses of the considered type of heat exchangers [1].

It was impossible to validate the code at the initial arrangement of the test stand. For this reason, the test stand was modernized within the current research project and the validation procedure became possible. A hot water supply module, as shown in Fig. 4, was built.

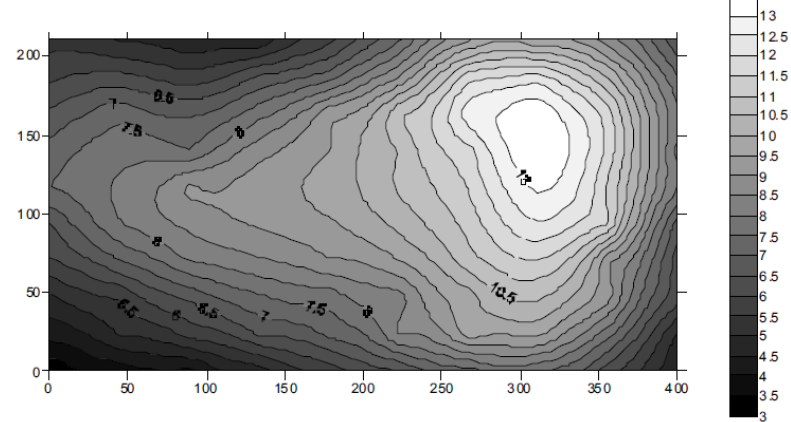

Fig. 3. Example air velocity distribution (in $\mathrm{m} / \mathrm{s}$ ) at the heat exchanger inlet

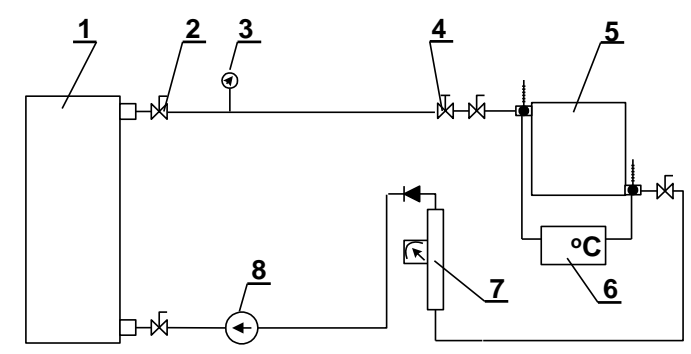

Fig. 4. Test stand - diagram of the hot water supply module 1 - electric boiler, 2 - cut-off valve, 3 - gauge, 4 - regulation valve, 5 - heat exchanger, 6 - temperature measuring system, 7 - flowmeter, 8 - circulation pump

The initial validation procedure showed significant differences between numerical and experimental results [2]. It is suggested that the discrepancies were caused by the method of the heat transfer coefficient determination. The gas-side heat transfer coefficient can be determined through numerical simulations performed for a numerical model of a repetitive fragment of the considered heat exchanger [3] or it can be computed using one of the available Nusselt number correlations.

The heat transfer coefficients on the liquid and on the gas side and the area of the heat transfer are the main parameters describing this type of heat exchangers. Determination of the liquid-side heat transfer coefficient does not pose a big problem. The turbulent flow inside the tubes is a well-recognized issue and most of the existing empirical correlations give comparable results [4]. The basic problem in the computations of such heat exchangers is to calculate the coefficient of the heat transfer from the finned surfaces to the gas. Due to the diversity of designs, it is impossible to formulate a universal correlation for the Nusselt number. It is difficult to select an appropriate relationship for a given geometry It is also difficult to select the characteristic dimensions. The differences in the heat transfer coefficient local values resulting from uneven flows of the mediums through the exchanger complicates the analysis additionally [1].

This paper focuses on an analysis of the in-house HEWES code sensitivity to the method of the heat transfer coefficient determination. The authors believe that the sensitivity analysis may be also useful for the evaluation of different methods of the heat transfer coefficient computation.

\section{Heat transfer coefficient computations}

\subsection{Application of the Nusselt number correlations}

A traditional analysis of the convective heat transfer for simple cases is based on the theory of similarity and an analysis of dimensions. The Nusselt number is a dimensionless form of the heat transfer coefficient and it is expressed as:

$$
N u=\frac{h \cdot L}{k}
$$

The Nusselt number general form at forced convection is described as follows:

$$
N u=a \cdot R e^{b} \cdot \operatorname{Pr}^{c}
$$

Constants a, b, and c in Eq. 2 depend on the case. It is very difficult to find an analytical solution for real cases. Therefore, extensive measurements are necessary. A statistical analysis of experimental results makes it possible to determine the values of the constants in Eq. 2 and to formulate a detailed empirical correlation. A large number of such relationships have been worked so far. It should be mentioned, however, that their application is limited to heat exchangers with designs the same as or very similar to those used in the experiments. Six formulae were tested as applicable for the heat exchanger under consideration [1, 4, 7-9]. The diagram presented in Fig. 5 explains the specific symbols used in Eqs. 3-12. 

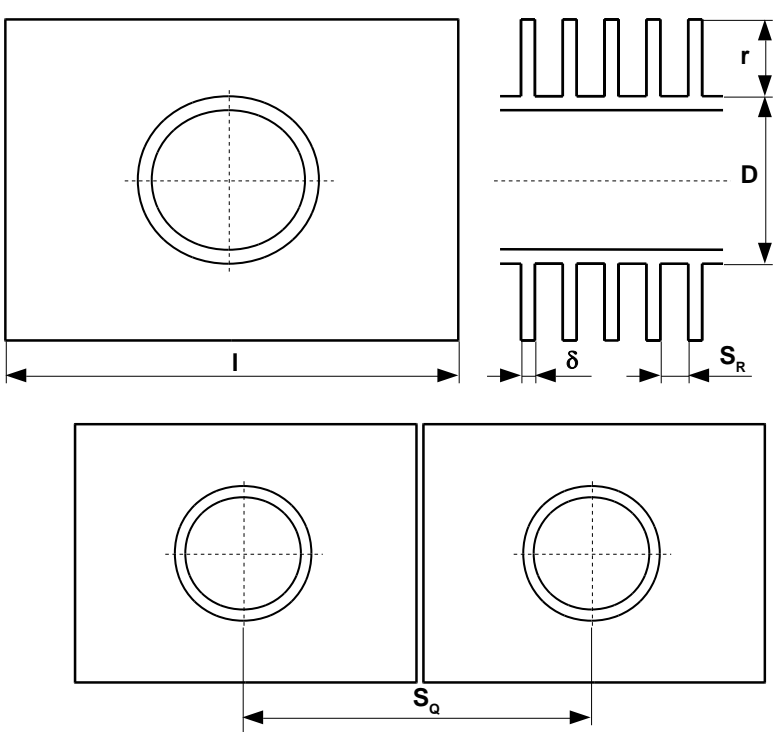

Fig. 4. Tube and fin characteristic dimensions

1. Berman correlation:

$$
N u=0.225 \cdot R e^{0.633}
$$

Equation 3 is valid for gas cooling. While considering the gas heating process, the considered values of the heat transfer coefficient should be by $50 \%$ higher.

2. Brigs and Young correlation:

$$
N u=0.134 \cdot \operatorname{Re}^{0.681} \operatorname{Pr}^{0.333}\left(\frac{S_{R}}{r}\right)^{0.2}\left(\frac{S_{R}}{\delta}\right)^{0.113}
$$

3. Schmidt correlation:

$$
N u=0.3 \operatorname{Re}^{0.625} \operatorname{Pr}^{0.333}\left(\frac{A_{f+t}}{A_{0}}\right)^{-0.375}
$$

where $A_{f+t}$ is the total surface area of the tube and the fins, and $\mathrm{A}_{0}$ is the surface area of a smooth, non-finned, tube.

\section{Paikert correlation:}

$$
\mathrm{Nu}=0.26 \operatorname{Re}^{0.6} \operatorname{Pr}^{0.333}\left(\frac{A_{0}}{A_{e}}\right)^{0.6}\left(\frac{A}{A_{G 0}}\right)^{-0.15}
$$

where:

$$
\begin{gathered}
\frac{A_{0}}{A_{e}}=\frac{S_{Q}\left(S_{R}+\delta\right)}{\left(S_{Q}-D\right) S_{R}+\left(S_{Q}-D-2 r\right) \delta} \\
\frac{A}{A_{G 0}}=1+\frac{2 r(r+D+\delta)}{D\left(S_{R}+\delta\right)}
\end{gathered}
$$

The characteristic dimension in Eqs. 3-6 is the tube outer diameter.

5. Norris and Spofford correlation [8]:

$$
N u=1.0 \cdot \operatorname{Re}^{\frac{1}{2}} \cdot \operatorname{Pr}^{\frac{1}{3}}
$$

The authors of Eq. 9 define the characteristic linear dimension as doubled length of the longitudinal flow path around the fin.
6. Kays and London correlation - the researchers conclude their studies on finned-tube banks using charts presenting the Colburn factor as a function of the Reynolds number [9]:

$$
S t \cdot \operatorname{Pr}^{2} / 3=f(R e)
$$

The Stanton number is known as the modified Nusselt number and it is defined as:

$$
S t=\frac{h}{u \cdot \rho \cdot c_{p}}=\frac{N u}{R e \cdot P r}
$$

The characteristic dimension in the considered case is the tube bank equivalent hydraulic diameter:

$$
d_{h}=4 l \frac{A_{f r}}{A_{f+t}}
$$

where $A_{\text {fr }}$ is the flow smallest free path surface area in between the exchanger tubes.

The relationships shown above were used to calculate the heat transfer coefficient for the air velocity values ranging from 2 to $20 \mathrm{~m} / \mathrm{s}$ and for the air temperatures of $10^{\circ} \mathrm{C}, 20^{\circ} \mathrm{C}$ and $30^{\circ} \mathrm{C}$. The range of the air parameters was established based on experiments. The results are presented in Fig. 6. It can be seen clearly that the results given by the relationships under consideration are very different.

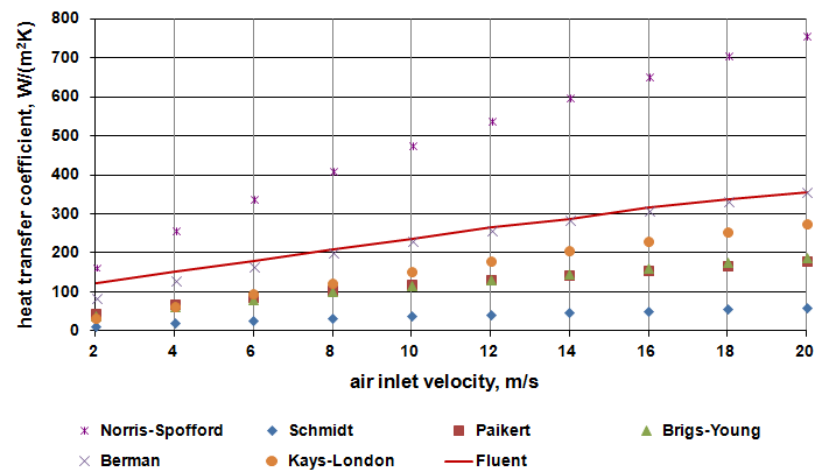

Fig. 6. Heat transfer coefficient calculation results (for the air temperature of $20^{\circ} \mathrm{C}$ )

The most significant difference is observed for the Norris and Spofford correlation, as well as for the Schmidt correlation. Application of the remaining Nusselt number correlations produced results closer to each other, but the differences still reach up to $200 \%$.

\subsection{Numerical simulations using a CFD program}

Two geometrical models were made for the numerical computations: one reflected a repetitive element of the considered heat exchanger and the other a repetitive segment. Both models are based on the geometry and dimensions of the tubes and the fins shown in Fig. 7. 


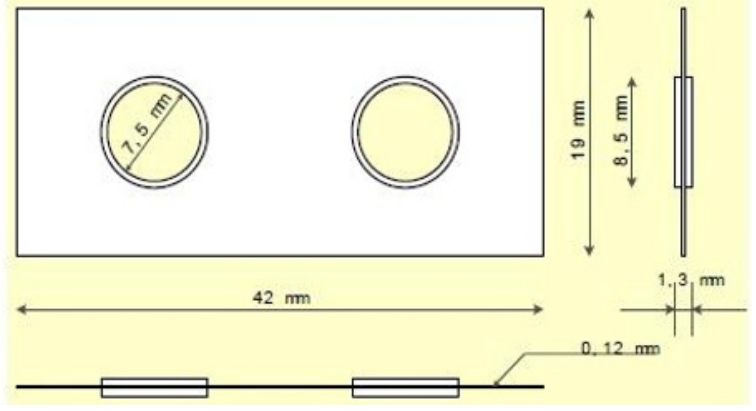

Fig. 7. Geometry and dimensions of the repetitive element

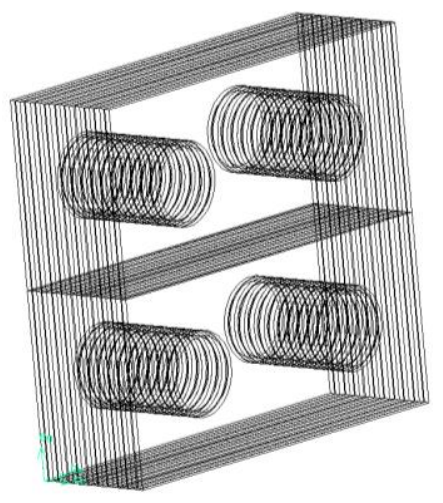

Fig. 8. Geometry of the repetitive segment of the heat exchanger

The simulations were performed using the ANSYS Fluent CFD code. It is assumed that the air inlet is parallel to the $\mathrm{x}$ axis of the model. Except the inlet and the outlet surfaces, all the remaining planes are assumed as symmetry planes. At first, the testing computations were performed to select the proper numerical mesh and the turbulence model. The following data were adopted for the computations: the air inlet temperatures of $10^{\circ} \mathrm{C}, 20^{\circ} \mathrm{C}$, and $30^{\circ} \mathrm{C}$, and the velocity values ranging from $2 \mathrm{~m} / \mathrm{s}$ to $20 \mathrm{~m} / \mathrm{s}$. The Reynolds Stress Model of turbulence was selected for basic computations.

The averaged value of the heat transfer coefficient on the air side is calculated based on the known temperature distribution of the fin and the tube surface areas and the average air temperature and the transferred heat flow rate. This can be written as:

$$
h_{a}=\frac{\sum_{i=1}^{n}\left(\dot{q}_{i} A_{i}\right)}{\sum_{i=1}^{n} A_{i}\left[\frac{\sum_{i=1}^{n}\left(T_{i} A_{i}\right)}{\sum_{i=1}^{n} A_{i}}-\frac{\sum_{j=1}^{m}\left(T_{a j} V_{j}\right)}{\sum_{j=1}^{m} V_{j}}\right]}
$$

The results, in comparison with the results calculated using the presented Nusselt number correlations, are shown in Fig. 6. It should be noted that the results obtained by means of the numerical model agree very well with the Berman correlation for the Nusselt number.

The values of the convective heat transfer coefficient on the air side obtained from the numerical experiment are higher than those obtained from the majority of the Nusselt number correlations. This may be due to the fact that excellent contact between the fin and the tube in the numerical model and no additional heat resistance resulting, for example, from the fin surface fouling are assumed.

It should also be noted that not all geometrical parameters of the numerical model of the analysed heat exchanger are perfectly in line with the geometry of the devices tested experimentally. The assumed boundary conditions also affect the obtained results. At lower air velocities, the discrepancies between the heat transfer coefficient values obtained from the equations and from the experiment are relatively bigger. This is due to the difficulty of modelling not fully developed turbulent flows.

\subsection{Utilization of the Wilson plot}

Application of the Wilson method makes it possible to determine the heat transfer coefficient mean value along the heat transfer surface. The term "Wilson plot" is used for various approximation methods of determination of the relationships between the temperature difference and the heat flux for either side of the heat exchanger by measuring the overall temperature difference between the fluids and the heat transfer rate [6].

The gas-side heat transfer coefficient for the considered cooler was determined using the traditional Wilson plot. A set of special experiments was planned and carried out. The water flow rate varied and the air flow parameters were kept constant during the experiments. Assuming that the heat flow rate is proportional to the temperature difference, the heat transfer coefficient has the same value for all the tests.

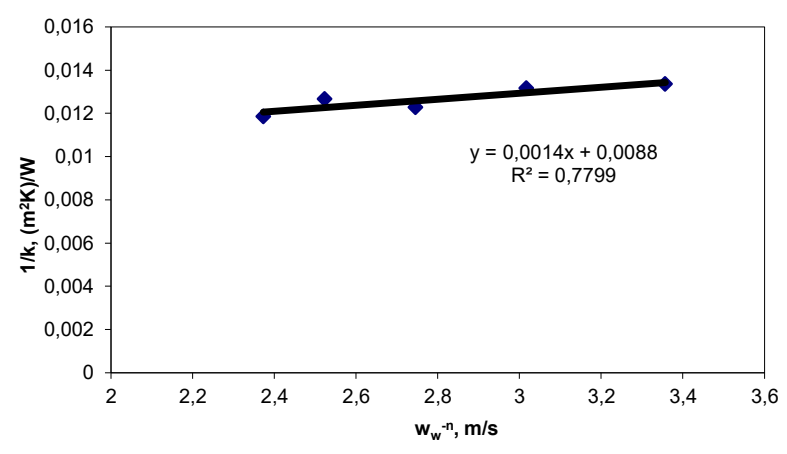

Fig. 9. Simple Wilson plot for one of the measuring series

An example Wilson plot for a selected set of experiments is presented in Fig. 9. According to the Wilson method, the value read out at the intersection of the trend line and the vertical axis is the sum of the tube wall thermal resistance and the thermal resistance on the gas side. Symbol $\mathrm{n}$ in the figure is a constant equal to 0.8 . The heat transfer coefficient value calculated for the presented data totals $113.7 \mathrm{~W} /\left(\mathrm{m}^{2} \mathrm{~K}\right)$.

\section{Results and discussion}

The HEWES code, developed for thermal and hydraulic analyses of fin-and-tube heat exchangers with a nonuniform flow of mediums, was used to evaluate the HTC determination methods. The mathematical model being 
the basis of the code utilizes the finite difference method. The governing equations are the mass and energy balances written for a repetitive element of the heat exchanger under consideration - this is a single fin with the adjacent section of the tube. The code was developed within the works presented in [1], and then it was validated experimentally [2]. The code was used recently for simulations of other fin-and-tube heat exchangers [10].

The evaluation was based on a comparison of the following parameters:

- total heat transfer rate,

- overall heat transfer coefficient,

- air outlet temperature,

- water outlet temperature.

The total heat flow rate is calculated from the water enthalpy drop:

$$
\dot{Q}=\dot{V}_{w} \rho_{w} c_{p w}\left(t_{w, \text { in }}-t_{w, o u t}\right)
$$

Water density $\rho_{\mathrm{w}}$ is determined for the outlet temperature. The average heat transfer coefficient is computed from the Péclet law:

$$
k_{l}=\frac{\dot{Q}}{L \cdot \Delta t_{\text {ave }}}
$$

where the average temperature difference is calculated as:

$$
\Delta t_{\text {ave }}=\varepsilon_{\Delta t} \cdot \Delta t_{m}
$$

The temperature difference correction factor $\varepsilon_{\Delta t}$ is determined based on [7], and $\Delta \mathrm{t}_{\mathrm{m}}$ is the logarithmic mean temperature difference.

The water outlet temperature is measured by a thermocouple, and the HEWES code calculates it as well, so the parameter is found easily.

The HEWES code also computes the average outlet temperature of air, but determination of the temperature experimental value requires averaging the parameter values measured in each measuring field:

$$
t_{a, \text { out }}=\frac{\sum_{i} A_{i} \cdot t_{a, i}}{\sum_{i} A_{i}}
$$

In equation $17, A_{i}$ stands for the measuring field surface area. It should be noted that the thermoanemometric sensor moves along the planes in front of and behind the heat exchanger. The planes are divided into a measuring grid consisting of identical rectangles representing the measuring fields. The air inlet and outlet velocity and temperature are measured in the middle of each measuring field.

The values of relative differences $\delta$ are computed for all of the four compared parameters to evaluate the HEWES code accuracy:

$$
\delta_{X}=\left|\frac{X_{\text {exp }}-X_{\text {num }}}{X_{\text {exp }}}\right| \cdot 100 \%
$$

where $\mathrm{X}_{\exp }$ is an experimental value of tested parameter, and $X_{\text {num }}$ is a computational value.

All the simulations were repeated 8 times to take account of all the methods and formulae for the heat

\begin{tabular}{|c|c|c|c|c|}
\hline Parameter $\rightarrow$ & $\dot{Q}$ & $\mathrm{k}_{\mathrm{l}}$ & $t_{a, \text { out }}$ & $t_{w, \text { out }}$ \\
\hline Unit & $\mathrm{kW}$ & $\mathrm{W} /(\mathrm{mK})$ & ${ }^{\circ} \mathrm{C}$ & ${ }^{\circ} \mathrm{C}$ \\
\hline \multirow[t]{2}{*}{ Experiment } & 13.6 & 62.9 & 40.2 & 54.7 \\
\hline & - & - & - & - \\
\hline \multirow[t]{2}{*}{ Berman } & 13.0 & 60.8 & 39.5 & 55.5 \\
\hline & $4.1 \%$ & $3.4 \%$ & $1.7 \%$ & $1.5 \%$ \\
\hline \multirow[t]{2}{*}{ Schmidt } & 11.1 & 51.9 & 37.9 & 57.4 \\
\hline & $18.1 \%$ & $17.5 \%$ & $5.7 \%$ & $5.0 \%$ \\
\hline \multirow[t]{2}{*}{ Paikert } & 11.6 & 54.2 & 38.5 & 56.9 \\
\hline & $14.5 \%$ & $13.9 \%$ & $4.2 \%$ & $4.1 \%$ \\
\hline \multirow{2}{*}{$\begin{array}{r}\text { Brigs-Young } \\
\delta \\
\end{array}$} & 12.7 & 59.0 & 39.0 & 56.1 \\
\hline & $6.5 \%$ & $6.2 \%$ & $2.9 \%$ & $2.5 \%$ \\
\hline \multirow{2}{*}{$\begin{array}{r}\text { Norris-Spofford } \\
\delta \\
\end{array}$} & 16.0 & 73.5 & 42.4 & 51.9 \\
\hline & $17.3 \%$ & $16.8 \%$ & $5.5 \%$ & $5.1 \%$ \\
\hline \multirow{2}{*}{$\begin{array}{r}\text { Kays-London } \\
\delta\end{array}$} & 12.8 & 59.6 & 39.4 & 55.7 \\
\hline & $5.8 \%$ & $5.2 \%$ & $2.1 \%$ & $1.9 \%$ \\
\hline \multirow[t]{2}{*}{ Wilson } & 12.4 & 57.9 & 38.9 & 56.3 \\
\hline & $8.5 \%$ & $7.9 \%$ & $3.2 \%$ & $2.9 \%$ \\
\hline \multirow[t]{2}{*}{ Fluent } & 14.1 & 64.9 & 40.6 & 54.3 \\
\hline & $3.5 \%$ & $3.2 \%$ & $1.1 \%$ & $0.8 \%$ \\
\hline
\end{tabular}

transfer coefficient determination described earlier. The results for two selected experimental cases are presented

\begin{tabular}{|c|c|c|c|c|}
\hline Parameter $\rightarrow$ & $\dot{Q}$ & $\mathrm{k}_{\mathrm{l}}$ & $t_{a, \text { out }}$ & $t_{w, \text { out }}$ \\
\hline Unit & $\mathrm{kW}$ & $\mathrm{W} /(\mathrm{mK})$ & ${ }^{\circ} \mathrm{C}$ & ${ }^{\circ} \mathrm{C}$ \\
\hline \multirow[t]{2}{*}{ Experiment } & 7.9 & 42.2 & 33.1 & 45.7 \\
\hline & - & - & - & - \\
\hline \multirow[t]{2}{*}{ Berman } & 7.6 & 40.8 & 32.7 & 46.2 \\
\hline & $3.9 \%$ & $3.2 \%$ & $1.3 \%$ & $1.1 \%$ \\
\hline \multirow[t]{2}{*}{ Schmidt } & 6.5 & 34.7 & 31.4 & 47.9 \\
\hline & $18.2 \%$ & $17.7 \%$ & $5.2 \%$ & $4.8 \%$ \\
\hline \multirow[t]{2}{*}{ Paikert } & 6.8 & 36.6 & 31.8 & 47.4 \\
\hline & $14.2 \%$ & $13.2 \%$ & $4.0 \%$ & $3.8 \%$ \\
\hline \multirow{2}{*}{$\begin{array}{r}\text { Brigs-Young } \\
\delta \\
\end{array}$} & 7.4 & 39.7 & 32.3 & 46.7 \\
\hline & $6.2 \%$ & $5.9 \%$ & $2.5 \%$ & $2.1 \%$ \\
\hline \multirow{2}{*}{$\begin{array}{r}\text { Norris-Spofford } \\
\delta\end{array}$} & 9.3 & 49.3 & 34.8 & 43.5 \\
\hline & $17.8 \%$ & $16.9 \%$ & $5.2 \%$ & $4.9 \%$ \\
\hline Kays-London & 7.5 & 40.3 & 32.5 & 46.4 \\
\hline$\delta$ & $5.3 \%$ & $4.6 \%$ & $1.8 \%$ & $1.5 \%$ \\
\hline \multirow[t]{2}{*}{ Wilson } & 7.3 & 39.0 & 32.1 & 46.8 \\
\hline & $8.1 \%$ & $7.6 \%$ & $2.9 \%$ & $2.5 \%$ \\
\hline \multirow[t]{2}{*}{ Fluent } & 8.2 & 43.5 & 33.4 & 45.4 \\
\hline & $3.3 \%$ & $3.0 \%$ & $0.9 \%$ & $0.7 \%$ \\
\hline
\end{tabular}
in Table 1 and Table 2.

Table 1. Evaluation analysis - results for Case 1

Table 2. Evaluation analysis - results for Case 2

Table 1 presents the results obtained from the experiment performed at the maximum volume flow of air $\left(5600 \mathrm{~m}^{3} / \mathrm{h}\right)$, the water volume flow of about $28 \mathrm{dm}^{3} / \mathrm{min}$ and the water inlet temperature of $90^{\circ} \mathrm{C}$. The biggest differences were observed while running the HEWES code with the Norris-Spofford and the Schmidt correlations, which give the highest and the lowest values 
of the heat transfer coefficient on the air side. The simplest Nusselt number correlation proposed by Berman as well as the CFD-based approach for the HTC determination give results closest to the experiment. The results indicate clearly that the HEWES code is sensitive to the HTC determination method. As this parameter concerns the air flow around the finned surface, the second experiment was carried out at the same water flow parameters, but with the minimum air volume flow (about $3000 \mathrm{~m}^{3} / \mathrm{h}$ ). The results of the comparative analysis for this experiment are listed in Table 2, and they are quite similar to the previous case. The best agreement between experimental and numerical results is found for the CFD model and the Berman correlation.

\section{CONCLUSIONS}

The results of the analyses prove that application of the available Nusselt number correlations to determine the HTC on the heat exchanger finned surfaces can produce significantly different results. In this case, there are no unequivocal criteria for the choice of a particular equation. It seems that the typical criterion based on the value of the Reynolds number may be insufficient. It should be added that with complex geometries there are too many variable parameters that can have a significant impact on the fluid flow and the heat transfer, and certainly the cited studies failed to include all these parameters. Moreover, taking account of the fact that many of the commonly used empirical correlations were formulated in the middle of the twentieth century, and considering the technological progress made since then, it can be expected that the possibilities of using them in relation to state-of-the-art devices may be rather limited. The use of computational fluid dynamics makes it possible to get complete information about the velocity, pressure and temperature fields in the device under consideration. The information can be used to verify the choice of the appropriate empirical relationship, or, in the case of large discrepancies in the obtained results, to identify the heat transfer coefficient for a specific geometry.

The results obtained by applying the calculated HTC values for simulations of experiments by means of the HEWES code indicate that the Berman correlation for the Nusselt number gives results close to experimental ones. The best results were obtained using the CFD-based method of the HTC determination.

This work was realized within the statutory research program of the Faculty of Energy and Environmental Engineering of the Silesian University of Technology.

\section{References}

1. R. Piątek, Thermal analysis of the plate fin-and-tube heat exchanger with a non-uniform inflow of mediums, (PhD dissertation, Institute of Thermal Technology, Silesian University of Technology, Gliwice 2003)
2. T. Bury, R. Piątek, J. Składzień, Experimental validation of the numerical thermal model of the cross-flow heat exchanger with unequal agent flow, ECOS, Cracow (2008)

3. T. Bury, J. Składzien,, The experimental and the numerical analysis of a ribbed heat exchanger with an unequal inlet of the air, Heat Transfer and Renewable Sources of Energy (2006), pp. 419-426

4. E. Kostowski, Heat transfer (Publishing House of the Silesian University of Technology, Gliwice 2000)

5. T. Bury, J. Składzień, R. Piątek, $13^{\text {th }}$ Symposium on the Heat and Mass Transfer, pp. 297-304 (2007)

6. J.W. Rose, Experimental Thermal and Fluid Science, 28, pp. 77-86 (2004),

7. E. Kalinowski, Heat transfer and heat exchangers, (Publishing House of the Wrocław University of Technology, 1995)

8. R. H. Norris, and W. A. Spofford, Trans. ASME, 64, pp. 489-496 (1942)

9. W. M. Kays, and A. L. London, Transactions of ASME, 76, pp. 387-396 (1954)

10. T. Bury, M. Hanuszkiewicz-Drapała, and K. Widziewicz, Heat Transfer Engineering, 39,13-14, pp. 1179-1191 (2018) 